\title{
Reducing Turfgrass Water Consumption using Sensor Nodes and an Adaptive Irrigation Controller
}

\author{
Scott Fazackerley, Student Member, IEEE \\ Department of Computer Science \\ University of British Columbia Okanagan \\ Email: scott.fazackerley@alumni.ubc.ca
}

\author{
Ramon Lawrence, Member, IEEE \\ Department of Computer Science \\ University of British Columbia Okanagan \\ Email: ramon.lawrence@ubc.ca
}

\begin{abstract}
This paper describes a complete wireless sensor and irrigation control system that reduces water consumption for residential turfgrass irrigation. It has been estimated that 50$75 \%$ of residential water use is for irrigation. Current systems are exceptionally poor at adapting irrigation to meet demand, primarily due to incomplete information for system operators who rely either on visual inspection or periodic irrigation programs. This results in over-watering and fertilizer and soil leaching. Our approach couples easy-to-deploy wireless soil moisture sensors nodes with an adaptive irrigation controller that waters on demand without user input. The result is a system that requires less user intervention, lowers water consumption, and adapts to changing climatic conditions.
\end{abstract}

\section{INTRODUCTION}

Despite the trend to xeriscape landscapes and low maintenance yards, there remains a considerable amount of turfgrass that requires irrigation. Massive amounts of water are used for irrigating parks, recreational areas, and golf courses. In semiarid regions with large populations such as California, Florida, the southwestern United States, and British Columbia's Okanagan Valley, between $60 \%$ and $75 \%$ of municipal water usage is attributed to residential turfgrass irrigation [1], [2]. The use of automatic and timed irrigation systems has made it easier to guarantee plants have adequate water but has also caused increased usage of water, often unnecessarily. Due to climate change, population growth, and overall increasing consumption, the price of water will increase as its availability is strained. Effective use of water for irrigation is critical.

Since the cost of water has been relatively low, there has been less effort in conservation and frugality. Consider a home owner with an automatic irrigation system who wants a green lawn. Common practice is to water every second day regardless of climate patterns. Some "sophisticated" systems have shut off systems based on recent rainfall (rainfall sensors) that have been shown to reduce water consumption significantly [3]. Systems that employ soil moisture sensors reduce water consumption even more [4]. However, these systems are costly to install especially on an existing lawn when the soil moisture sensors must be connected by wires to the controller.

The basic question for the home owner is: When and by how much should I water the lawn to keep it green and use the least amount of water possible? Without proper data, this question is hard to answer. Home owners tend to favor over-watering in such conditions. Despite the benefits of soil moisture sensors for residential irrigation, few users employ such techniques due to the cost and difficulty of installation.

With current technology, it is possible to build a data collection system that uses soil moisture sensors (available from numerous vendors) to determine soil moisture content. Current technology is inadequate for several reasons. First, the cost of scientific sensors is prohibitive for many environments (especially residential use), and the products are not easily configurable or deployed. Many products rely on wires for data transfer from sensors and wireless products are costly. Recent work has shown that wireless networks can be used to measure soil moisture for large scale agriculture but fail to address how watering decisions are made using the sensing network [5], [6]. There is a requirement for an overall solution that handles the complete cycle of data collection, analysis, and then automatic irrigation system control. Our work has built a closed loop system with an irrigation controller that dynamically schedules irrigation based on input from wireless soil moisture sensor nodes.

The contents of this paper are as follows. Section 2 provides an overview of a typical residential irrigation system and the limitations of current technology. Section 3 describes the wireless soil moisture sensor nodes and the adaptive irrigation controller. An experimental evaluation is in Section 4 and the paper closes with future work and conclusions.

\section{BACKGROUND}

A residential landscape is divided into different irrigation zones. A zone is an area that is watered at the same time. Zones are created based on different irrigation needs (lawn, shrubs, flower and garden beds). The number of sprinkler heads that can be run simultaneously is limited by the available water pressure and flow rate. Each zone has an associated valve that when opened supplies water to the zone. An irrigation controller is a device that allows the user to control when and how often each zone is watered.

Low-end controllers have simple scheduling mechanisms that allow a user to specify one or more watering programs which include a start time for the program and the length of watering time for each zone. More costly controllers allow for more programs and zones. The issue is that the user now must decide how much water to apply to each zone. Typically, users decide to water zones on a daily or two day interval 
often based on local regulations and recommendations. Users rarely adjust the programs unless the effects of insufficient watering are visually noticeable, even though the amount of water required varies significantly throughout the season based on temperature and precipitation [7].

Previous work has shown that water use efficiency can be improved through the addition of add-on sensors to existing irrigation controllers or through the use of more sophisticated controllers [3], [4], [8], [9], [10]. The types of control systems that are used in common practice can be classified as rainfall shutoff sensors $(R S)$, soil moisture sensors $(S M S)$ and evapotranspiration controllers (ET) [9].

Rainfall and soil moisture sensors dramatically reduce the amount of water consumed [3], [11]. The sensor functions as an override device with an existing controller. These systems still rely on a user defined program and will only bypass the program under certain conditions. The weakness of these approaches is that they only block an existing program from occurring, they do not create their own irrigation programs based on the data collected. These systems often require an extensive cable network to connect sensors to the controller.

On-demand controllers improve on the basic SMS controller approach. These systems are extremely expensive and typically use wired SMS. With on-demand controllers, two set points are used for water content. The user defines a lower and upper water content set point. The controllers will water when the water content in the soil reaches the lower point and will terminate watering once the water content reaches the upper limit [11]. An alternate approach used with ET controllers attempts to estimate the plant water demand based on local weather patterns. This information is provided as a service to users for specific locations and controllers require a method of accessing daily evapotranspiration models [9], [11].

Our approach uses soil moisture sensors to determine the soil water content and schedules watering events on demand. Unlike current SMS or on-demand controllers, our system just does not water until the water content reaches an upper threshold. Instead, the control method is based on a water budget [12] with a Deficit Irrigation [13] penalty strategy to calculate the amount of water required per zone to re-establish water content levels without over watering. Based on the amount of water required by the soil, the system dynamically schedules the irrigation time. A penalty model prevents over watering due to unexpected inputs of water.

Unlike $E T$ systems, no external data is required which may not directly reflect local conditions. If used in an area with a large variance in terms of local climate, the performance of the unit may lead to less than optimal results. Extensive testing in North Carolina has shown that ET systems produced no savings in water due to overestimation in terms of evapotranspiration demands [8].

With on-demand SMS systems, currently only available in large scale commercial systems, controllers will water until the water content reaches the upper set point [11]. However, this may still lead to over-watering as water moves through soil at a very slow rate. Thus, the system may continue to water longer than required until the sensor readings reflect the new water applied.

Attempts have been made to use wireless sensor technologies in irrigation and agricultural applications [14], [5], [15], [6]. These systems primarily perform data collection, but no closed loop control of the irrigation system. Our approach collects data and uses that to drive the irrigation and reduce water consumption.

\section{SYSTEM DESCRIPTION}

The goal of the system is to be low-cost and easy-todeploy for residential users. The system consists of three components: a controller node responsible for controlling and scheduling irrigation events, a sensing node that is responsible for scheduling and reporting soil moisture readings, and a soil moisture sensor. In each zone of interest, a wireless soil moisture sensor is placed in the rooting zone of the plants. This soil moisture sensor collects readings at a regular interval and relays the readings back to the controller. Each sensor node is about $5 \mathrm{~cm} \times 7.5 \mathrm{~cm} \times 10 \mathrm{~cm}$. The node is encased in waterresistant packaging and slightly submerged under the soil.

\section{A. Wireless Sensor Node}

While there exist numerous sensor nodes, they often provide just a wireless gateway [16] and require the construction and addition of a peripheral interface card to support the required functionality. Our goal was to design a system that was complete for use in environmental monitoring applications and supports a variety of common sensors without the need for additional hardware. The custom platform also allows for design control over power consumption, routing and data collection strategies, and program development that is difficult using off-the-shelf products.

Each node has a wireless radio and an Atmel Mega644p processor chosen because of its low power consumption and suitable program space. The wireless radio is a Digi International XBee radio which is based on the 802.15.4 standard [17]. Each node can support a two port 10-bit analog to digital converter, an eight port 12-bit analog to digital converter, an eight port output driver, and three pulse counters. This allows for a sensor node to interact with the environment and conduct numerous functions. Each sensing node can connect up to eight soil moisture sensors and report their status to the controller node, eliminating the need for extensive wiring. Nodes also support on-board temperature and power monitoring. The soil moisture sensor used is an EC-5 (Decagon Devices) providing 0.1\% resolution in water content [18]. The node is powered by three AA batteries. The sensor board is shown in Figure 1. Based on power models for the sensor node, nodes will last the length of a growing season on one set of batteries. Each node wakes from sleep at a minute interval, performs a reading from the soil moisture sensors, stores the results locally, and transmits results to the controller.

\section{B. Controller Node}

The controller uses the same sensor node hardware but has the additional task of controlling the irrigation. A daughter 


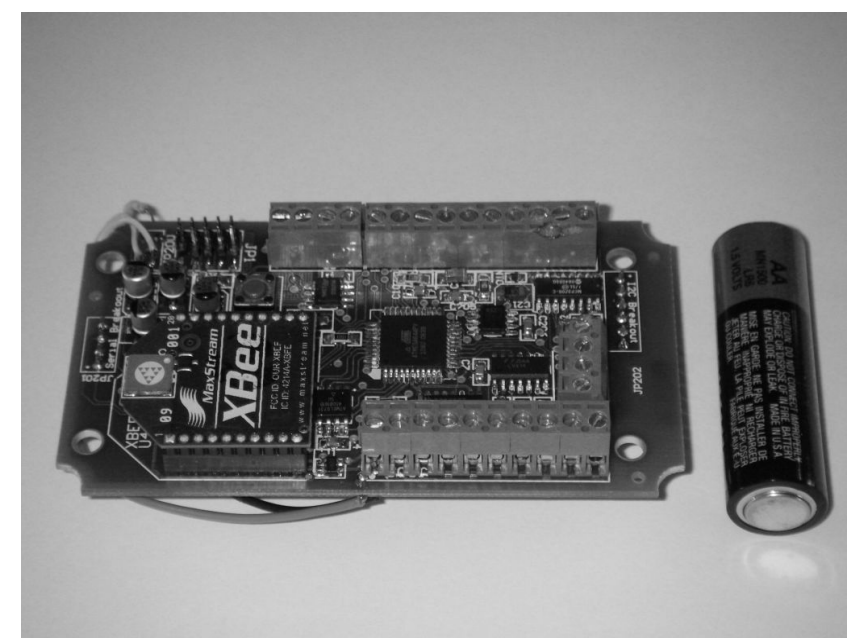

Fig. 1. Sensor Mote: Internal Circuit Board

board interfaces with the node to provide a suitable interface for the solenoid values as well as a switching power supply to convert 24 VAC to suitable DC voltage levels. The controller node and the valve system are powered by 24 VAC.

The controller has a user interface for setting acceptable irrigation times and controlling the valves for each zone. The controller analyzes the data provided by the sensor nodes and determines how much (long) to water and schedules an irrigation event. The data can also be extracted to a PC for analysis. The main controller monitors water flow through a flow meter that is attached to a pulse counter input. The controller has a real-time clock that it uses to control watering start and end times. As each program event is determined, it is added to a watering queue. Since only one zone can be watered at a time, a program to be executed is placed on the queue until it is available to be serviced.

The cost of each completed node including the controller is approximately $\$ 100$ in small quantities excluding the cost of the soil moisture sensor. This is a significant reduction in cost as the lowest cost controller that is able to perform on-demand watering is approximately $\$ 3000$ [11].

\section{Adaptive Irrigation Program}

To schedule an event the controller determines when and how much water is required. The system triggers a watering event when the current soil moisture reading, $\theta$, is less than or equal to $\theta_{T O}$ where:

$$
\theta_{T O}=\frac{\theta_{F C}+\theta_{P W P}}{2}
$$

$\theta_{F C}$ is the field capacity which is the maximum amount of water a soil can retain. Any excess water drains way and is wasted. $\theta_{P W P}$ is the permanent wilting point which is the point at which roots can no longer extract water from the soil. Using a deficit irrigation strategy, our model provides slightly less water than required by the lawn as research has shown that the introduction of small crop stress actually can improve the quality of turfgrass [19], [20].
The calculation of how much water to apply depends on the irrigation system setup. Controllers can only control the amount of time to water a zone. The amount of water applied to a zone in a given time depends on the flow rate, the zone area, and the application efficiency. Flow rate can be estimated based on water pressure and sprinkler head configuration or directly measured using a flow meter. Application efficiency $\left(A_{e}\right)$ is the percentage of water that is successfully delivered into the rooting zone relative to the amount of water applied.

An estimate using a flow meter to calculate flow rate, a known zone area, and a continuously updated application efficiency value is:

$$
\text { time }=\left[E_{\text {irr }}+\frac{\left(\theta_{f c}-\theta\right) \times d_{\text {sensor }}}{A_{e}}\right] \times \frac{A}{Q}
$$

where $\theta_{F C}$ is soil moisture level at field capacity, $\theta$ is the current moisture status of the soil, $d_{\text {sensor }}$ is the sensor depth, $A$ is the area of the zone, and $Q$ is the flow rate. In addition to losses due to $A_{e}$, applications will loose $0.005 \mathrm{~m}$ of water due to evaporation and soil surface interactions [12]. All applications will have this loss and is labeled as $E_{i r r}$.

For example, if the sensor is placed at $0.1 \mathrm{~m}, \theta_{F C}=$ $0.35, \theta_{T O}=0.26$, the flow rate is $0.008 \mathrm{~m}^{3}$ per minute, the application efficiency $\left(A_{e}\right)$ is 0.76 and the zone area is $9 \mathrm{~m}^{2}$, the controller will generate a watering event for this zone for a period of 18.9 minutes.

$$
\begin{aligned}
\text { time }= & {\left[0.005 m+\frac{(0.35-0.26) \times 0.1 m}{0.76}\right] \times \frac{9 m^{2}}{0.008 m^{3} / \mathrm{min}} } \\
& =18.9 \text { minutes }
\end{aligned}
$$

The system then performs the watering event and waits a certain time, called the blackout time, where the water is allowed to diffuse through the soil. Once the blackout time expires, the controller determines how much water was delivered into the profile compared to the estimated amount through sensor measurements. The controller uses the differences between the estimated and actual soil water content values to update $A_{e}$ for each watering event to accurately characterize dynamic losses in the system. With this method, the actual water content will never exceed the field capacity level under normal irrigation. By preventing water content from rising above the field capacity point, water waste is minimized.

\section{EXPERIMENTAL RESUlts}

An irrigation test site was constructed consisting of two 3 meter x 3 meter plots of turfgrass. The controller was placed above the ground in close proximity to the valve control box. Each zone was monitored by a flow meter and the controller uses historical actual flow in the calculation of watering events. The test system is using spray heads which typically have an $A_{e}$ of $76 \%$ [21] but this does not consider other loss sources. In addition to adaptive scheduling, the controller performed a standard timed program option which was used 


\begin{tabular}{|c|c|c|}
\hline & Adaptive & Control \\
\hline Total Volume (litres) & 2915.4 & 6471.6 \\
Total depth (meters) & 0.324 & 0.719 \\
Est. Evap. loss (meters) & 0.065 & 0.265 \\
Effective Daily Avg. (meters) & 0.00498 & 0.00873 \\
\hline
\end{tabular}

TABLE I

ADAPTIVE WATERING PROGRAM RESULTS

with the control zone. No daily watering restrictions were in place from the local watering authority thus a daily watering program was used. The amount of water applied was based on recommended watering from [21] based on the estimated demand using historical data. The depth of water applied took into consideration the actual efficiency for the control zone. The system recorded watering information, soil moisture, and flow data for each zone. Data was collected from July 10, 2009 to September 1, 2009. We compared the water consumption of a conventional zone using a recommended watering program versus water consumption of the adaptive watering program. Total applied water for each zone was tracked.

The experimental area is a semi-arid environment and during the test period, the average maximum daily temperature was $33.14^{\circ} \mathrm{C}$ as reported by a nearby agricultural weather station. Long periods of little or no precipitation were experienced presenting extended periods of high water demand. During the two month period, only 6 days of rain were recorded with only 3 days producing more than $5 \mathrm{~mm}$ of precipitation which translates to only $0.0029 \mathrm{~m}$ of effective precipitation over the test period.

The adaptive watering program delivered 54\% less water with no noticeable effect on visual appearance within and between the test plots during the test period. The adaptive system delivered a total depth of $0.324 \mathrm{~m}$ of water whereas the control zone delivered a total depth of $0.719 \mathrm{~m}$ of water. The cumulative depths of applied water for the adaptive and control programs are in Figure 2. The system also contributed to water savings by only watering a total of 13 days during the two month period, effectively reducing loss through evaporation. The results are summarized in Table I.

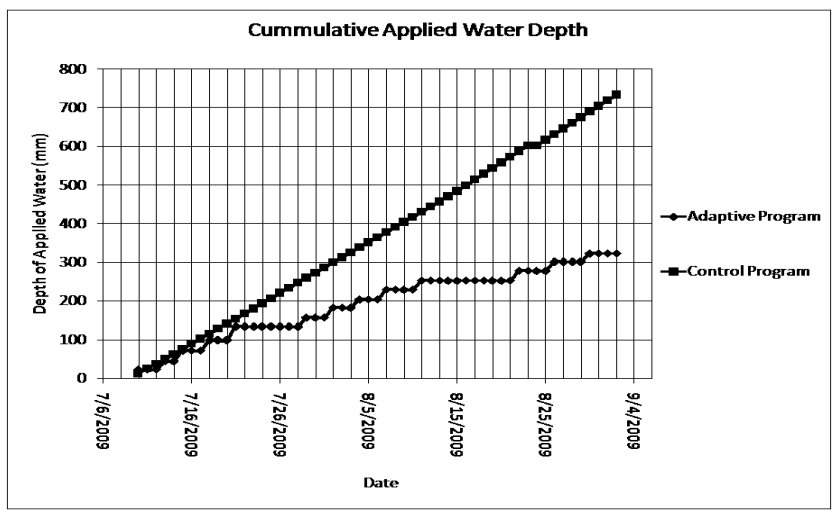

Fig. 2. Cumulative Water Depths for Adaptive and Control Programs

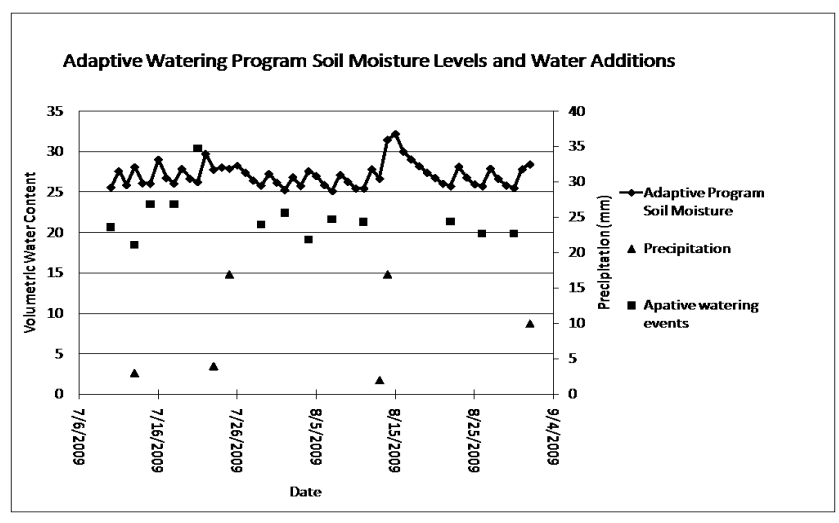

Fig. 3. Water Additions for Adaptive Watering Program

Of particular note is how the adaptive program responded to rainfall events. Figure 3 shows how the soil moisture and watering events are effected by unscheduled additions of water through rainfall. It can be seen that after a rainfall event, watering events did not take place for several days as the turfgrass was able to extract existing water in the soil.

The adaptive irrigation program operated in an efficient fashion. The system had no interruptions in service. During the test period, the depth of water applied as determined by the adaptive program was compared to the actual measured ET demand at the agricultural weather reporting station. The measured ET represents the actual depth of water that was used by the crop. During the test period, the actual ET demand was $0.254 \mathrm{~m}$ of water. Our watering program delivered and effective amount of $0.2589 \mathrm{~m}$ of water; a difference of only $2 \%$ which can be considered to be statistically insignificant due to micro-climate variations between the test site and the weather reporting station.

The quality of the turf was graded using the subjective National Turfgrass Evaluation Procedure [2], [22]. No discernible difference in turfgrass quality was noticed between the control and test plots, with both being of high quality.

\section{CONCLUSiON}

Efficient residential water use is a key part of a responsible water management strategy. Water consumption can be significantly reduced in turfgrass irrigation by using soil moisture sensing technology. A design for an adaptive irrigation controller using low cost wireless sensor nodes for both controlling the irrigation program and monitoring the soil moisture status has been presented. Significant savings in water use were realized with the adaptive watering program. The ease of use due to the lack of programming, as well as the considerable lower cost compared to comparable products, makes this system attractive for acceptance by residential users. Future work includes deployment of the technology in a large sensor network in a golf course in the 2010 growing season. The network nodes will use multi-hop geographical routing for communicating between sensor nodes and controllers. 


\section{ACKNOWLEDGMENT}

The authors would like to acknowledge NSERC and the Martha Piper Fund who supported this research.

\section{REFERENCES}

[1] D. Degen, "Water Sustainability: City of Kelowna Water Utility," Presentation for Okanagan Water Stewardship Council, June 2007.

[2] M. B. Haley, M. D. Dukes, and G. L. Miller, "Residential Irrigation Water Use in Central Florida," Journal of Irrigation and Drainage Engineering, vol. 133, no. 5, pp. 427-434, 2007. [Online]. Available: http://link.aip.org/link/?QIR/133/427/1

[3] B. Cardenas-Lailhacar, M. D. Dukes, and G. L. Miller, "Expanding Disk Rain Sensor Performance and Potential Irrigation Water Savings," Journal of Irrigation and Drainage Engineering, vol. 134, no. 2, 2008.

[4] B. Cardenas-Lailhacar, M. D. Dukes, and G. Miller, "Sensor-Based Automation of Irrigation on Bermudagrass during Wet Weather Conditions," Journal of Irrigation and Drainage Engineering, vol. 134, no. 1, pp. $120-128,2008$

[5] J. McCulloch, P. McCarthy, S. M. Guru, W. Peng, D. Hugo, and A. Terhorst, "Wireless sensor network deployment for water use efficiency in irrigation," in REALWSN '08: Proceedings of the workshop on Realworld wireless sensor networks. New York, NY, USA: ACM, 2008, pp. $46-50$

[6] Y. Zhou, X. Yang, L. Wang, and Y. Ying, "A Wireless Design of Low-Cost Irrigation System Using ZigBee Technology," in International Conference on Networks Security, Wireless Communications and Trusted Computing (NSWCTC '09). Los Alamitos, CA, USA: IEEE Computer Society, 2009, pp. 572-575.

[7] T. V. der Gulik and J. Nyvall, "Crop Coefficients For Use In Irrigation Scheduling," Resource Management Branch, B.C. Ministry of Agriculture, Foods and Fisheries, Tech. Rep. Factsheet No. 577.100-5, October 2001.

[8] G. L. Grabow, A. Vasanth, D. Bowman, R. L. Huffman, and G. L. Miller, "Evaluation of Evapotranspiration-Based and SoilMoisture-Based Irrigation Control in Turf," in Proceedings of the World Environmental and Water Resources Congress 2008, vol. 316, no. 40976. ASCE, 2008, pp. 117-117. [Online]. Available: http://link.aip.org/link/?ASC/316/117/1

[9] T. Olmsted and M. D. Dukes, "Irrigation," Conserve Florida Water Clearinghouse, University of Florida, Tech. Rep., 2008.

[10] M. Shedd, M. D. Dukes, and G. L. Miller, "Evaluation of Evapotranspiration and Soil Moisture-Based Irrigation Control on Turfgrass," in World Environmental and Water Resources Congress 2007, vol. 243, no. 40927. ASCE, 2007, pp. 238-238. [Online]. Available: http://link.aip.org/link/?ASC/243/238/1

[11] S. C. A. Office, W. R. P. Technical Resources Center, and O. S. Group, "Weather and Soil Moisture Based Landscape Irrigation Scheduling Devices," U.S. Department of the Interior, Bureau of Reclamation, Tech. Rep., August 2007.

[12] J. Nyvall, "Sprinkler Irrigation Scheduling Using a Water Budget Method," Resource Management Branch, B.C. Ministry of Agriculture, Foods and Fisheries, Tech. Rep., May 2004.

[13] E. Fereres and M. A. Soriano, "Deficit Irrigation for Reducing Agricultural Water Use," J. Exp. Bot., vol. 58, no. 2, pp. 147-159, 2007. [Online]. Available: http://jxb.oxfordjournals.org/cgi/content/abstract/58/2/147

[14] Y. Kim, R. Evans, and W. Iversen, "Remote Sensing and Control of an Irrigation System Using a Distributed Wireless Sensor Network," IEEE Transactions on Instrumentation and Measurement, vol. 57, no. 7, pp. 1379-1387, July 2008.

[15] F. Pierce and T. Elliott, "Regional and on-farm Wireless Sensor Networks for Agricultural Systems in Eastern Washington," Computers and Electronics in Agriculture, vol. 61, no. 1, pp. 32 - 43, 2008. [Online]. Available: http://www.sciencedirect.com/science/article/B6T5M4PGXF0V-1/2/d39c7c4c4804ab27cabd6cce0c94d880

[16] J. Polastre, R. Szewczyk, and D. Culler, "Telos: enabling ultra-low power wireless research," in Information Processing in Sensor Networks, 2005. IPSN 2005. Fourth International Symposium on, April 2005, pp. 364 369.

[17] IEEE Computer Society, "IEEE Std. 802.15.4-2007," August 2007, Available: http://standards.ieee.org/getieee802/ download/802.15.4a-2007.pdf.
[18] "Decagon devices inc," 2008, Available: http://www.decagon.com/.

[19] C. Baldwin, H. Liu, L. McCarty, W. Bauerle, and J. Toler, "Response of Six Bermudagrass Cultivars to Different Irrigation Intervals," HortTechnology, vol. 16, no. 3, pp. 466-470, 2006. [Online]. Available: http://horttech.ashspublications.org/cgi/content/abstract/16/3/466

[20] J. E. Jordan, R. H. White, D. M. Vietor, T. C. Hale, J. C. Thomas, and M. C. Engelke, "Effect of Irrigation Frequency on Turf Quality, Shoot Density, and Root Length Density of Five Bentgrass Cultivars," Crop Sci, vol. 43, no. 1, pp. 282-287, 2003. [Online]. Available: http://crop.scijournals.org/cgi/content/abstract/cropsci;43/1/282

[21] T. V. der Gulik, "Landscape Sprinkler Irrigation Scheduling Calculator Users Guide," Irrigation Industry Association of British Columbia, Tech. Rep., February 2009.

[22] NTEP Turfgrass Evaluation Workbook. Beltsville, MD: NTEP Turfgrass Evaluation Workshop, October 1998 